\title{
Three-dimensional analysis of an orthodontic delta spring
}

\author{
Fábio Rodrigo Mandello Rodrigues*, Paulo César Borges, Marco Antônio Luersen, Marcelo do Amaral \\ Ferreira
}

\begin{abstract}
Introduction: The purpose of this study was to analyze the force system, moment-force ratios (M/F) and von Mises stresses in an orthodontic delta spring using a 3D finite element model. The M/F ratio produced by an orthodontic spring is related to the different types of tooth movement that are likely to occur in the sagittal and occlusal planes. Methods: Analyses were performed using a 3D finite element model, and a data acquisition system was used to validate the numerical results. Results: Reactive forces between 0.0 and $2.0 \mathrm{~N}$ were observed along the $\mathrm{x}$-axis, while null values were observed along the $\mathrm{y}$ - and $\mathrm{z}$-axes. The maximum activation that ensured geometric stability and mechanical stresses below the elastic limit of the material was $10.0 \mathrm{~mm}$. Conclusions: The results indicate that a delta spring can provide (i) uncontrolled tipping for activation of less than $1.0 \mathrm{~mm}$; (ii) controlled counterclockwise tipping for activation between 1.0 and $4.5 \mathrm{~mm}$; (iii) translation for activation between 4.5 and $5.0 \mathrm{~mm}$; and (iv) controlled clockwise tipping in the sagittal plane for activation between 5.0 and $10.0 \mathrm{~mm}$. No tooth movement was observed in the occlusal plane for the M/F ratios observed.
\end{abstract}

Keywords Delta orthodontic spring, Finite element analysis, Moment-force ratio.

\section{Introduction}

In orthodontic practice, teeth are moved to correct malocclusion or to change their position for therapeutic purposes (De Franco et al., 1976; Koenig and Burstone, 1974). Tooth displacement can be produced by means of friction systems (i.e., systems in which the tooth and a bracket slide along a metal archwire) or frictionless systems (i.e., orthodontic retraction springs).

Sectional springs can be used to retract cuspids (De Franco et al., 1976; Ferreira et al., 2013) and as part of a segmented arch (Burstone, 1982) that uses support points to produce a system of weak, predictable forces. Cantilevers and retraction springs are also included within this mechanical system when the goal is to close spaces between teeth in a controlled manner. It is important that retraction springs are activated without resultant plastic deformation to the wire, as they will otherwise be unable to return to their original shape during deactivation and will therefore be ineffective in producing a particular desired movement.

To gain an understanding of their behavior following activation, retraction spring dynamics have been analyzed in both two and three dimensions. Several orthodontic spring geometries have been proposed and tested, with the T-loop being the most popular (Ferreira et al., 2008).

The elucidation of techniques to control force systems, moments and moment-to-force (M/F) ratios has led to the development of a wide variety of orthodontic spring designs for use in clinical treatment.
Examples include orthodontic springs made with superelastic alloys, such as the modified T-loop (Bourauel et al., 1997), the delta spring (Ferreira et al., 2005) and triangular loops (Katona et al., 2006).

Satisfactory analysis of an orthodontic spring requires the observation of various parameters, including the center of resistance $\left(\mathrm{C}_{\text {res }}\right)$ and center of rotation $\left(\mathrm{C}_{\mathrm{rot}}\right)$ (Raboud et al., 1997). A single force applied at the $\mathrm{C}_{\text {res }}$ results in translation in the direction of that force. In orthodontic studies, the $\mathrm{C}_{\text {res }}$ is the center of resistance when the tooth is seated in the bone. It is located at approximately one third to one half of the distance between the alveolar crest and the apex and does not change position. For free bodies, the $\mathrm{C}_{\text {res }}$ is equivalent to the center of mass. The $\mathrm{C}_{\text {rot }}$ is the point around which all other points on the tooth rotate, and it can change depending upon the force system (forces and moments) acting on the tooth.

If gables are inserted at the spring's extremities, the forces and moments following initial activation are increased. This initial activation produces a system of vertical, horizontal and torsional forces that are jointly responsible for tooth movements. Thus, a detailed understanding of this system is extremely useful for the design of orthodontic appliances and planning of clinical treatment.

Studies show that the ability to control tooth movement using orthodontic devices is dependent upon an understanding of the forces and moment-toforce ratios $(\mathrm{M} / \mathrm{F})$ present in a given system, as well 
as the subsequent quantification and control of these parameters. Without this knowledge, overall treatment may be adversely affected (Chen et al., 2010).

A powerful tool used in orthodontics is finite element analysis. The finite element method (FEM) involves the general characterization of a system to better understand it. To accomplish this characterization, the original system is divided for analysis into small individual parts that exhibit relatively simple behavior and then rebuilt as a whole after characterizing these components (Zienkiewicz and Taylor, 2000).

The use of FEM techniques in orthodontics is well established. Examples of FEM applications include dental implant research (Guan et al., 2011); orthodontic open-coil spring force analysis (Fraunhofer et al., 1993); orthodontic device design based on resultant forces and moments (Ferreira et al., 2008); dentomaxillofacial structural analysis using $3 D$ model analysis of segmented T-loop spring behavior (Lotti et al., 2006); numerical nonlinear analysis of orthodontic springs (Raboud et al., 1997); analysis of the effects of anterior retraction loop position on the forces produced and applied on canines in L-loops (Geramy et al., 2012); study of the intensity and direction of three-dimensional forces in orthodontic wire (Fotos et al., 1987); and other designs and analyses of orthodontic springs (Chen et al., 2010; De Franco et al., 1976; Hutton, 2004; Kojima and Fukui, 2012).

The orthodontic spring described here is the delta loop, which was originally proposed by Ferreira et al. (2005). Through finite element analysis, this loop was found to have null reactive forces along the $\mathrm{y}$-axis, providing good geometric stability in the direction under which it was activated. However, to our knowledge, there is no 3D analysis of this type of orthodontic spring in the literature, justifying the choice of this model for our study.

According to Ausiello et al. (2001), 3D FEM is widely used for the mechanical analysis of complex structures, such as the response of natural systems under different loads and conditions. Additionally, this method of analysis has been widely adopted to study biological systems, with its use increasing in recent decades due to its better geometric detail relative to 2D FEM.

As stated by Romeed et al. (2006), the main differences between the use of 2D and 3D FEM are related to geometric complexity, the purpose of the analysis and the accuracy required in the results. 3D analyses are able to capture more complex geometries more efficiently, but accurate mesh refinement control can be impaired by the greater complexity of the generated model.
Xavier and Ballester (2013) noted that 2D FEM analysis has the advantage of requiring less computational time, although there can be limitations in representing geometric complexities of the studied model. Though a longer computational time and subsequent need for more efficient computing equipment is required of $3 \mathrm{D}$ analysis, this approach is justified by the authors herein, so as to obtain a closer representation of reality when examining orthodontics with more complex geometries.

As the geometry of the delta loop proposed in this work is not simple, with various curves and the presence of an upper loop, 3D analyses are needed to determine mechanical stresses at specific points (e.g., inner face of the loop, fixation regions and folds) and to obtain forces and moments in all directions.

In addition, in most studies of orthodontic delta springs in the literature (Ferreira et al., 2005, 2013), 2D analysis restricted to the sagittal plane is performed, i.e., the analysis is restricted to the following: i.) the result of forces in the $x$ and $y$ directions, ii.) the moment about the $\mathrm{z}$-axis and, iii.) the $\mathrm{M} / \mathrm{F}$ ratio within only the $x z$ plane.

A comparison between forces and moments found in the literature using 2D FEM (Ferreira et al., 2013) and those found in this research by 3D FEM is presented later in the text.

The aim of this study was to perform a comprehensive numerical analysis for a delta retraction spring and to determine the resultant forces and moments in the three axes (x, y, z), as well as the M/F ratio for the occlusal plane, as presented in the literature for T-loop orthodontic springs (Raboud et al., 1997).

\section{Methods}

\section{Numerical method}

The numerical method used here consisted of the following two general steps:

- Solid modeling of the device (delta spring) using computer aided design (CAD) software;

- Simulations using 3D finite element analysis to determine the reactive forces and moments produced by the spring in the three axes $(\mathrm{x}, \mathrm{y}, \mathrm{z})$.

The spring was modeled, and its nonlinear (large deformation) behavior was analyzed in 3D with solidelement FEM techniques. The spring (Figure 1a) had a rectangular cross section measuring $0.016 \times 0.022$ in $(0.4065 \times 0.5588 \mathrm{~mm})$ and was manufactured from beta titanium (titanium-molybdenum) alloy (TMA) with a yield strength of $1240 \mathrm{MPa}$ and a longitudinal 
elastic modulus of 69 GPa (Ferreira et al., 2013). The 3D model of the spring is shown in Figure $1 \mathrm{~b}$.

After modeling the spring geometry, the next step was to generate a finite element mesh. Therefore, a convergence study was conducted beforehand to choose a reliable mesh. For a fixed activation value $(10.0 \mathrm{~mm})$, five meshes with different degrees of refinement were created and compared. As the geometry of the spring is relatively complex, it was not possible to either generate regular meshes or to exactly control the total number of elements. Additionally, two different types of 3D elements were used in the meshes: tetrahedrons and hexahedrons, both with quadratic interpolation. Table 1 shows the number of elements, $F_{x}, M_{z}, M_{y}$ and the maximum von Mises stress for the five meshes. As the number of elements increases, the values stabilize, indicating convergence. Furthermore, the differences in the results between meshes \#4 and \#5 after accounting for all parameters are less than $1.2 \%$. In light of these results and to achieve a compromise between computational time and accuracy, mesh \#4 was selected for analysis in the remainder of this work. Figure 1c shows the corresponding mesh, which has
1766 elements and 3992 nodes. Figure 1d presents the deformation needed to mount the spring on the brackets. The interbracket distance used was $24.0 \mathrm{~mm}$.

\section{Experimental system}

For the experimental analysis, a platform consisting of strain gauges mounted to a complete Wheatstone bridge was employed. The force and moment values were acquired using a data acquisition system and LabView software (National Instruments). Figure 2 shows an experimental test being performed on the spring.

The experimental equipment was able to measure reactive forces along the $x$ - and $y$-axes and the reactive moment about the $z$-axis.

\section{Results}

\section{Stress analysis}

Figures $3 \mathrm{a}$ and $3 \mathrm{~b}$ show the equivalent von Mises stresses in all regions of the spring for zero activation (i.e., the spring mounted in the brackets) and $12.0 \mathrm{~mm}$



(a)
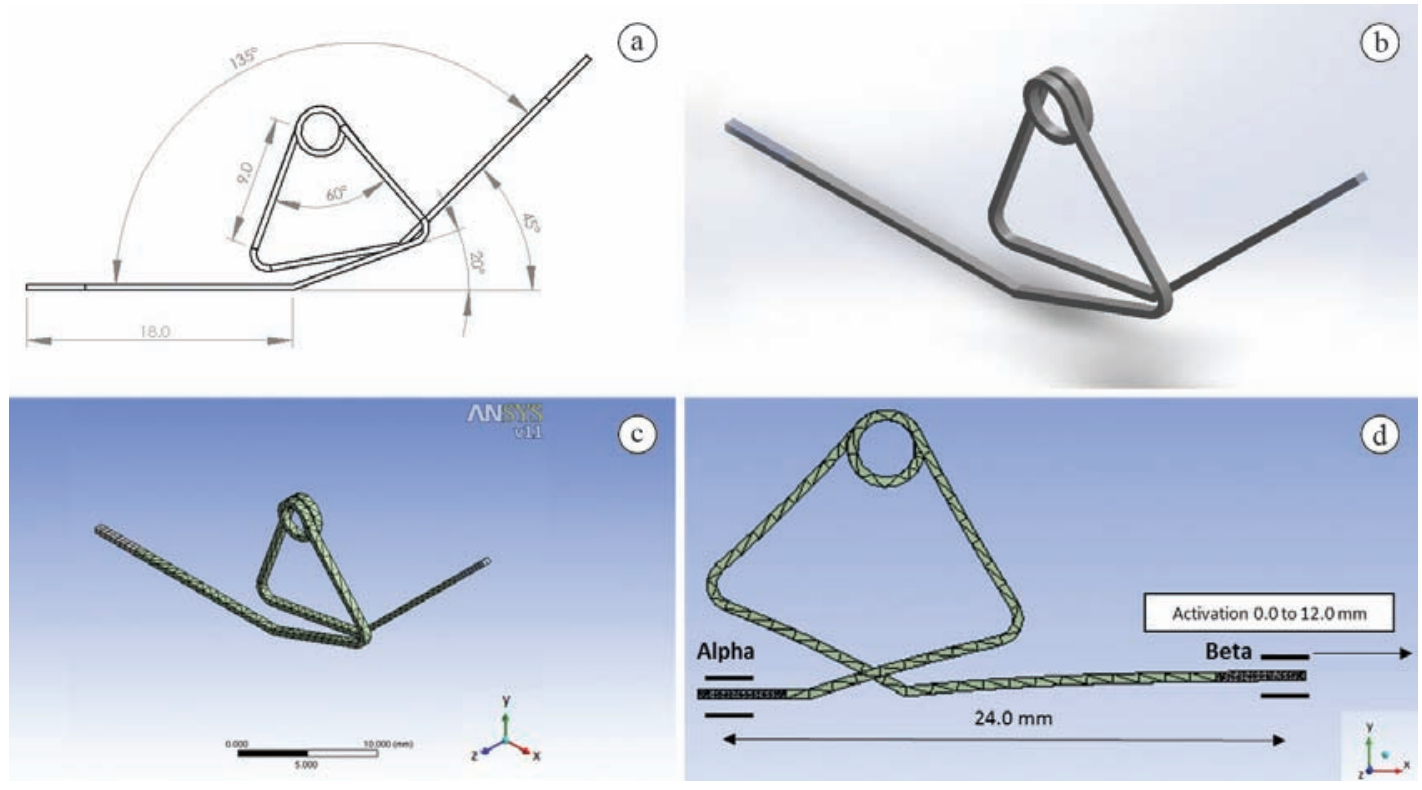

Figure 1. Design of the orthodontic delta spring: a) Dimensions (mm); b) 3D model (SolidWorks $\left.{ }^{\circledR}\right)$; c) Finite element mesh (Ansys ${ }^{\circledR}$ Workbench); d) Activation position and interbracket distance.

Table 1. Number of elements, $F_{x}, M_{z}, M_{y}$ and maximum von Mises stress for all meshes.

\begin{tabular}{cccccc}
\hline Mesh & $\begin{array}{c}\text { Number of } \\
\text { elements }\end{array}$ & Mz (N.mm) & My (N.mm) & $\begin{array}{c}\text { Fx (N) } \\
\text { (MPa) }\end{array}$ \\
\hline $\mathbf{1}$ & 593 & 8.99 & 1.51 & 1.91 & 1.88 \\
$\mathbf{2}$ & 1102 & 8.93 & 1.51 & 1.54 & 1.89 \\
$\mathbf{3}$ & 1623 & 8.93 & 1.72 & 1.88 & 1000 \\
$\mathbf{4}$ & 1766 & 8.93 & 1.74 & 1.87 \\
$\mathbf{5}$ & 2128 & 8.92 & & & 1017 \\
\hline
\end{tabular}



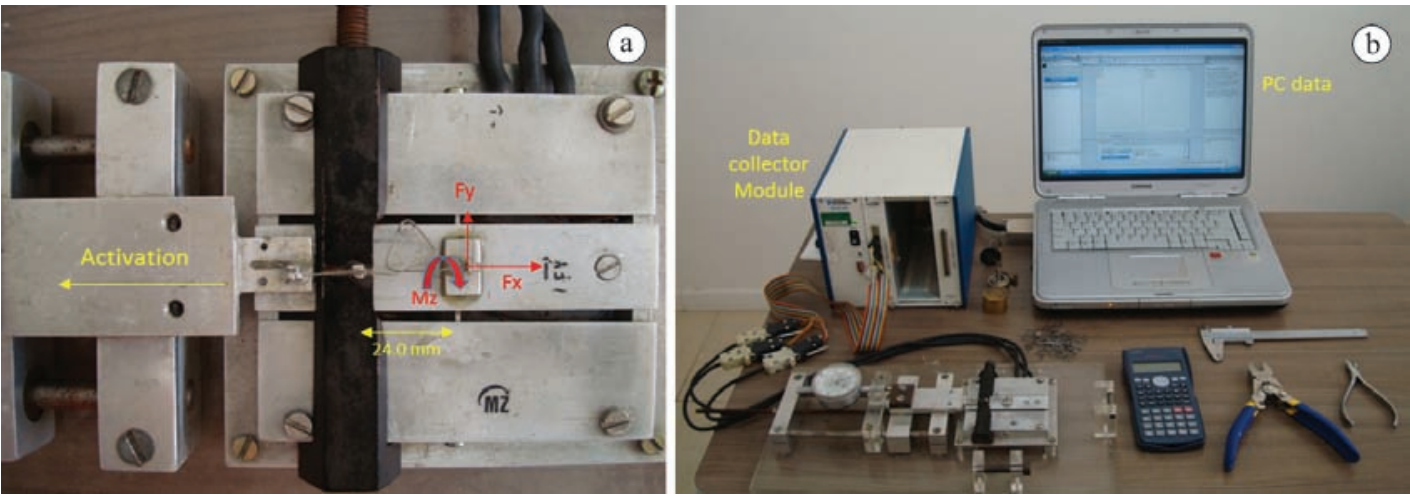

Figure 2. Experimental apparatus: platform (a) and complete system (b).
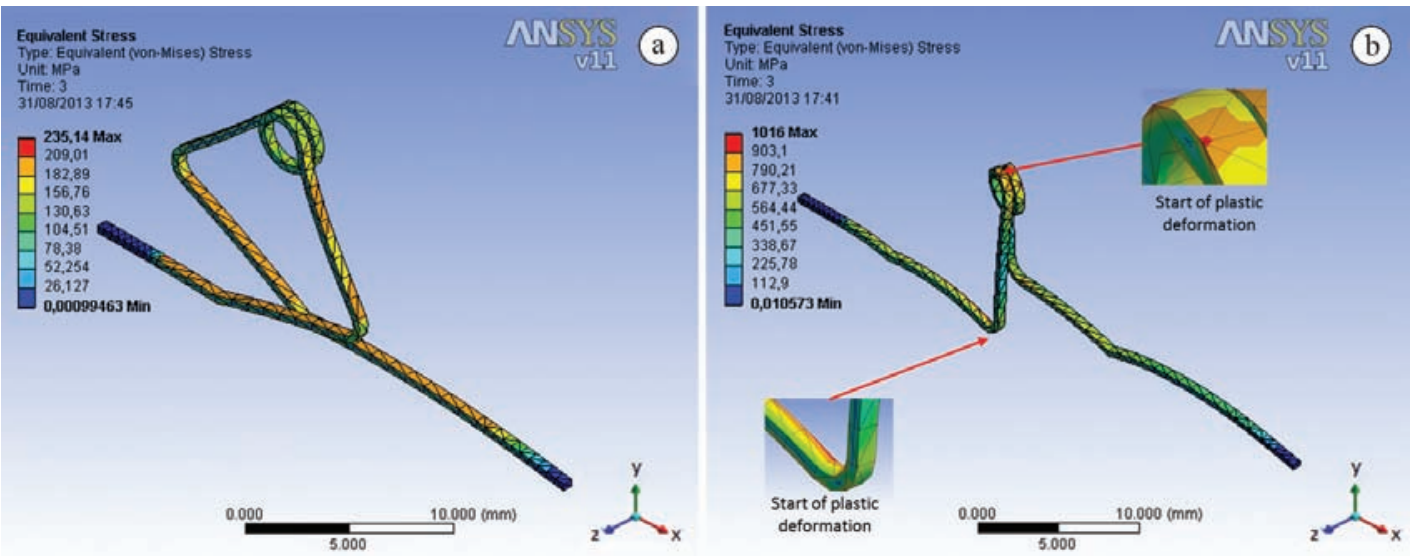

Figure 3. Von Mises stresses: a) for zero activation; b) for $12.0 \mathrm{~mm}$ activation.

activation, respectively. Maximal stresses occur at $232 \mathrm{MPa}$ in the preactivation position and between 1000 and $1016 \mathrm{MPa}$ for $12.0 \mathrm{~mm}$ activation. For activation above $12.0 \mathrm{~mm}$, the yield stress of the alloy is exceeded, i.e., the material in the wire begins to deform plastically. Thus, to avoid plastification, we limited activation to $10.0 \mathrm{~mm}$.

Plastic deformation occurs only at localized points: the upper part of the loop and both lower vertices.

Activation values for orthodontic springs should not result in the elastic limit of the spring being exceeded and are typically between 2.0 and $12.0 \mathrm{~mm}$ for L-loop, T-loop, triangular and delta geometries (Ferreira et al., 2013; Techalertpaisarn and Versluis, 2013).

\section{Analysis of reactive forces}

Activation at the beta end of the spring (Figure 1d) produced deformations in the spring and equivalent reaction forces at the constrained end (alpha end). These forces are important in identifying spring parameters, such as the $\mathrm{M} / \mathrm{F}$ ratio.
The resultant force along the $\mathrm{x}$-axis as a function of activation can be seen in Figure 4a.

As expected, $\mathrm{F}_{\mathrm{x}}$ increases with activation. Using Lab Fit software and Microsoft Excel, the following equation representing the relation between $F_{x}$ and activation was obtained.

Equation 1 - Reactive force along the $\mathrm{x}$-axis:

$$
F x=0.0015 a^{2}+0.174 a+0.0082
$$

where

$\mathrm{F}_{\mathrm{x}}[\mathrm{N}]$ is the reactive force acting along the $\mathrm{x}$-axis; $\mathrm{a}[\mathrm{mm}], 0 \leq \mathrm{a}<12.0$, is the activation.

\section{Reactive moments}

The value of each reactive moment and the corresponding forces were determined using 3D finite element modeling with activations in the range of 0 to $12 \mathrm{~mm}$; moment-versus-activation curves were then generated (Figure 4b). The graph depicts the moments about the z-axis $\left(\mathrm{M}_{\mathrm{z}}\right)$, which, along with 
the reactive forces along the $\mathrm{x}$-axis $\left(\mathrm{F}_{\mathrm{x}}\right)$, provide the $\mathrm{M}_{\mathrm{z}} / \mathrm{F}_{\mathrm{x}}$ ratio for tooth movement in the sagittal plane.

The moment about the $y$-axis $\left(M_{y}\right)$ has a maximum value of $1.0 \mathrm{~N} . \mathrm{mm}$ and is directly related to dental movements in the occlusal plane, with the force acting along the $\mathrm{x}$-axis $\left(\mathrm{F}_{\mathrm{x}}\right)$. Finally, the moment about the $\mathrm{x}$-axis $\left(\mathrm{M}_{\mathrm{x}}\right)$ is zero and therefore may be neglected in this study.

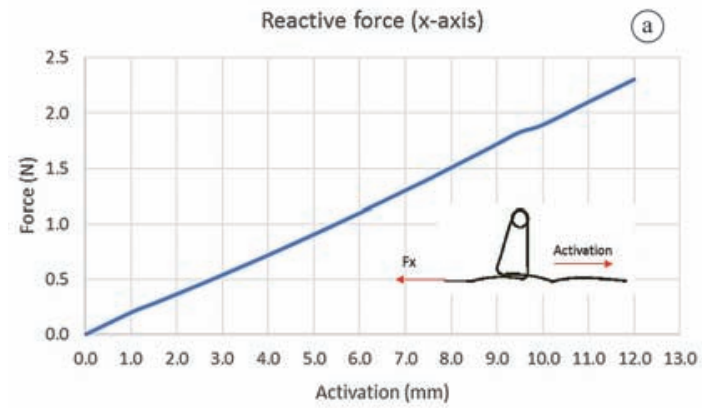

\section{M/F Ratio}

The values of reactive forces and moments obtained using the procedure described above allow the $\mathrm{M} / \mathrm{F}$ ratios in the sagittal $\left(\mathrm{M}_{\mathrm{z}} / \mathrm{F}_{\mathrm{x}}\right)$ and occlusal $\left(\mathrm{M}_{\mathrm{y}} / \mathrm{F}_{\mathrm{x}}\right)$ planes to be plotted against activation and the corresponding equations to be defined for the delta orthodontic spring. Figures $5 b$ and $5 d$ show the M/F ratios for the sagittal and occlusal planes, respectively, while Figures 5a

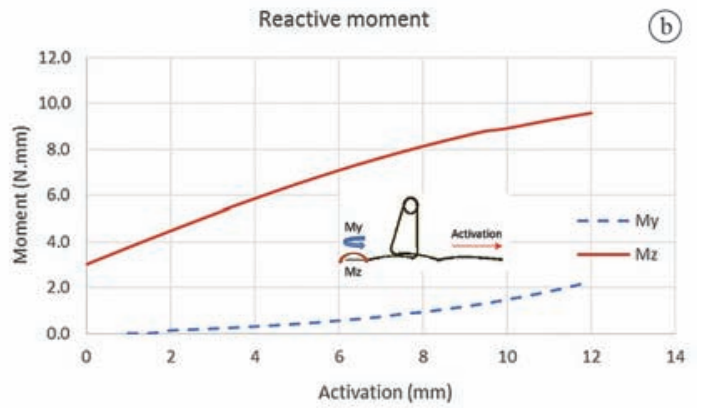

Figure 4. a) Resultant force $\left(\mathrm{F}_{\mathrm{x}}\right)$ versus activation; b) Reactive moment versus activation.

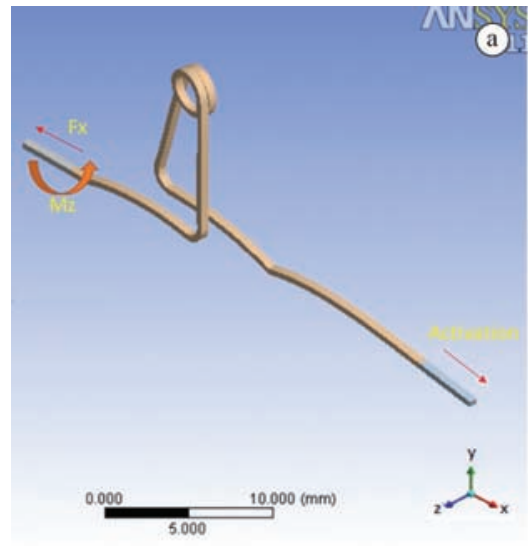

$\mathrm{Mz} / \mathrm{Fx}$ ratio - Sagittal view
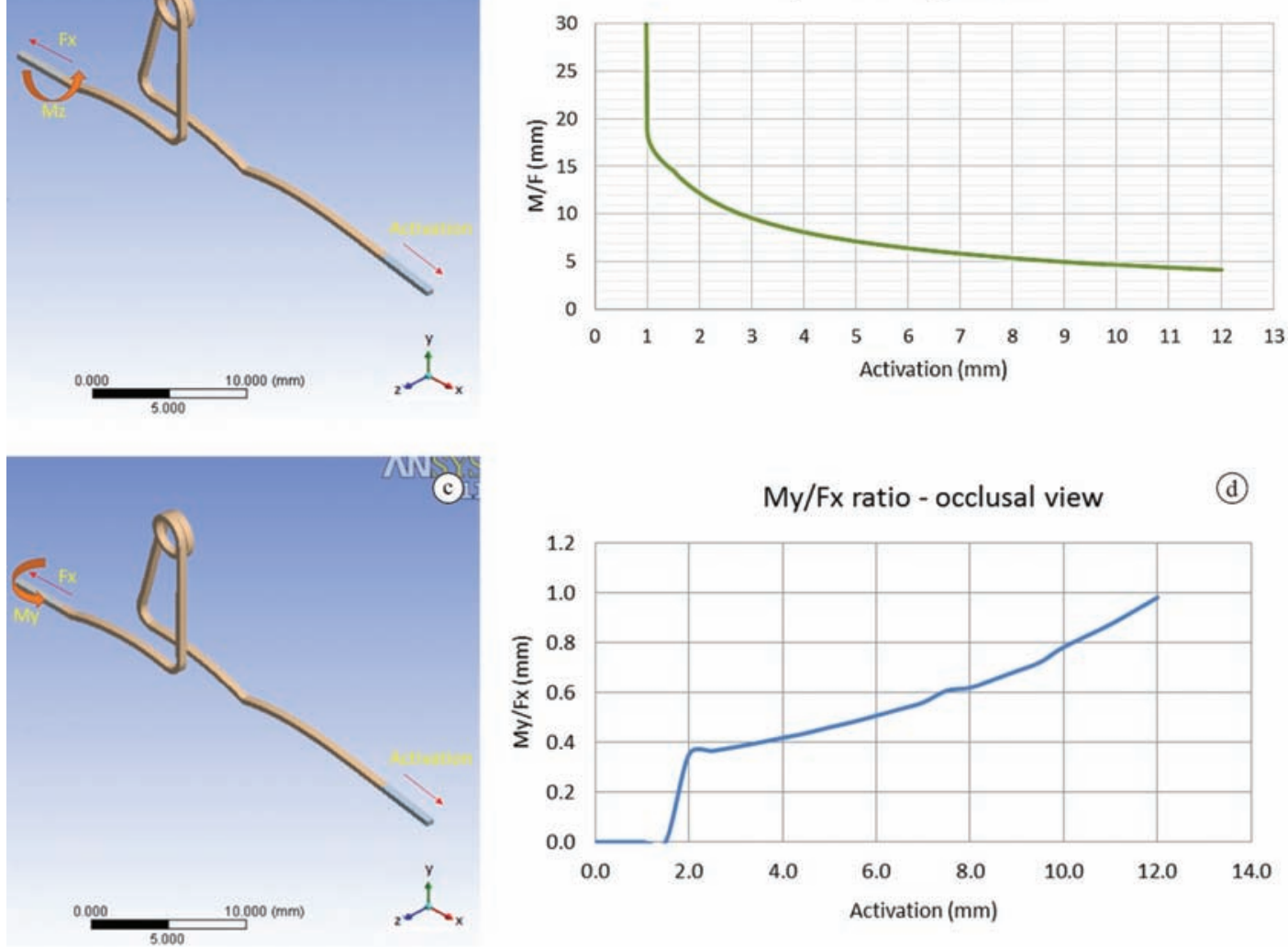

My/Fx ratio - occlusal view

(d)

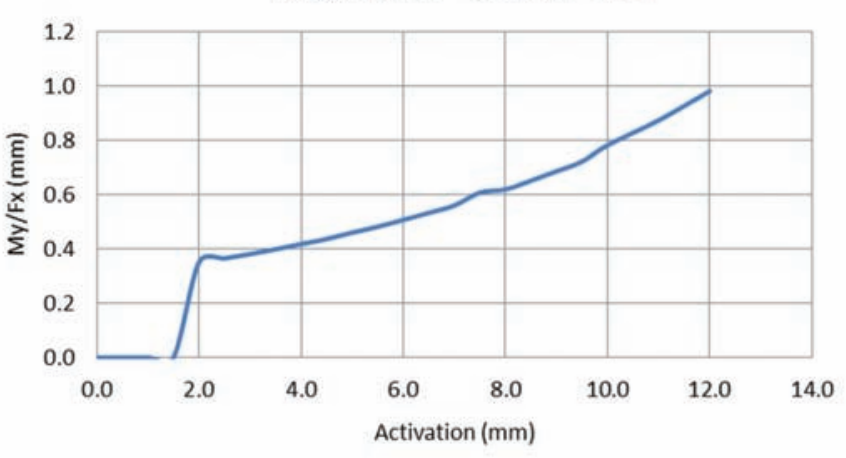

Figure 5. a) Active force and moment in the sagittal plane; b) $M_{z} / F_{x}$ versus activation; c) Active force and moment in the occlusal plane; d) $\mathrm{M}_{\mathrm{y}} / \mathrm{F}_{\mathrm{x}}$ versus activation. 
and $5 c$ depict the directions in which the forces and moments act. Equations 2 and 3 demonstrate the M/F ratio as a function of activation.

Equation $2-\mathrm{M} / \mathrm{F}$ ratio (sagittal plane) as a function of activation:

$\left(\frac{\mathrm{Mz}}{\mathrm{Fx}}\right)=\left(\frac{1000+2052.96 \mathrm{a}-69.944 \mathrm{a}^{2}}{1+162.799 \mathrm{a}+74.741 \mathrm{a}^{2}-0.81 \mathrm{a}^{3}}\right)$

Equation $3-\mathrm{M} / \mathrm{F}$ ratio (occlusal plane) as a function of activation:

$\left(\frac{M y}{F x}\right)=\frac{\left(0.006163-0.00791 a^{2}-0.005325 a^{4}+0.00342 a^{6}\right)}{\left(1-0.499 a^{2}+0.059 a^{4}+0.00575 a^{6}-1.897 a^{8}\right)}$

where

$\left(\frac{M z}{F x}\right)[\mathrm{mm}]=$ moment-force ratio (sagittal plane).

$\left(\frac{M y}{F x}\right)[\mathrm{mm}]=$ moment-force ratio (occlusal plane).

$\mathrm{M}_{\mathrm{z}}[\mathrm{N} \cdot \mathrm{mm}]=$ moment about $\mathrm{z}$-axis.

$\mathrm{M}_{\mathrm{x}}[\mathrm{N} \cdot \mathrm{mm}]=$ moment about $\mathrm{y}$-axis.

$\mathrm{F}_{\mathrm{x}}[\mathrm{N}]=$ reactive force along $\mathrm{x}$-axis.

$\mathrm{a}[\mathrm{mm}], 1.0 \leq \mathrm{a} \leq 12.0$, = activation.

\section{Validation of the numerical model}

To validate the numerical model, forces and moments were measured using the experimental apparatus described in the Methods section. Due to constraints

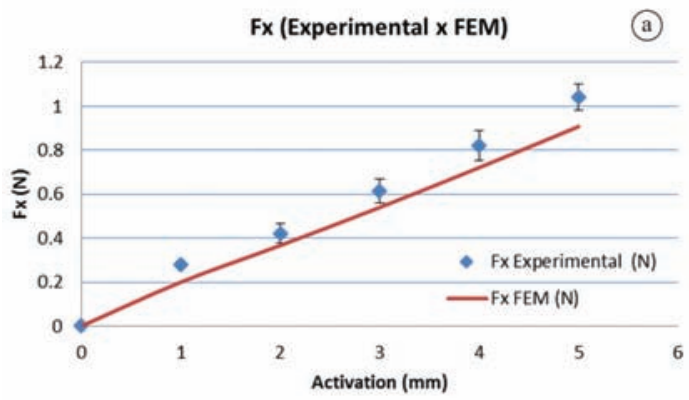

imposed by the experimental system, only the sagittal plane was considered. Student's t distribution with a $5 \%$ significance cut-off was used to obtain the results shown in Figures 6a, 6b and 6c. Table 2 shows the results of the statistical analysis of the experimental data. The error bar depicts the standard deviation.

The experimentally measured forces and moments were higher than those found numerically, most likely due to crystallographic changes in the metallurgical structure and residual stress produced by cold working conditions during the manufacturing process (i.e., plastic deformation). The moment-force ratio, which is directly related to tooth movement, varied little between the two methods.

\section{Discussion}

According to Raboud et al. (1997), dental movements in the sagittal plane can be classified as follows:

- Tooth translation $\left(\mathrm{M}_{\mathrm{z}} / \mathrm{F}_{\mathrm{x}}=8.5 \mathrm{~mm}\right)$;

- Uncontrolled clockwise root tipping $(\mathrm{M} / \mathrm{F}=0.0)$

- Controlled clockwise root tipping $\left(0<\mathrm{M}_{\mathrm{z}} / \mathrm{F}_{\mathrm{x}}\right.$ $<8.5 \mathrm{~mm}$ );

- Controlled counterclockwise crown tipping $\left(\mathrm{M}_{\mathrm{z}} / \mathrm{F}_{\mathrm{x}}>8.5 \mathrm{~mm}\right)$;

- Uncontrolled counterclockwise crown tipping $\left(\mathrm{M}_{\mathrm{z}} / \mathrm{F}_{\mathrm{x}} \rightarrow \infty\right)$



(c)

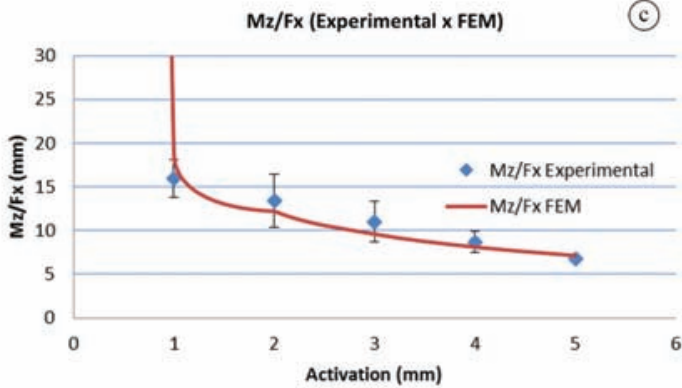

Figure 6. a) Reactive force along the x-axis versus activation (numerical and experimental); b) Reactive moment around the z-axis versus activation (numerical and experimental); c) $\mathrm{M}_{\mathrm{z}} / \mathrm{F}_{\mathrm{x}}$ versus activation (numerical and experimental). 
Table 2. Experimental reactive force (x-axis), reactive moment (z-axis) and $\mathrm{M}_{z} / \mathrm{F}_{\mathrm{x}}$ ratio $(n=10)$.

\begin{tabular}{cccccc}
\hline Activation $(\mathbf{m m})$ & Force $(\mathbf{N})$ & Standard deviation & Standard error & Minimum & Maximum \\
\hline $\mathbf{0}$ & 0 & 0 & 0 & 0 & 0 \\
$\mathbf{1}$ & 0.279 & 0.0163 & 0.0051 & 0.2738 & 0.3252 \\
$\mathbf{2}$ & 0.421 & 0.0436 & 0.0138 & 0.3766 & 0.5308 \\
$\mathbf{3}$ & 0.614 & 0.0539 & 0.0171 & 0.5308 & 0.7107 \\
$\mathbf{4}$ & 0.822 & 0.0691 & 0.0219 & 0.7621 & 0.9677 \\
$\mathbf{5}$ & 1.04 & 0.0593 & 0.0188 & 0.9419 & 1.1219 \\
\hline & Moment (N.mm) & Standard deviation & Standard error & Minimum & Maximum \\
\hline $\mathbf{0}$ & 3.507 & 0.8740 & 0.2764 & 2.32 & 5.0284 \\
$\mathbf{1}$ & 4.4482 & 0.8405 & 0.2658 & 3.4812 & 6.0598 \\
$\mathbf{2}$ & 5.6343 & 0.8682 & 0.2746 & 4.1258 & 6.5756 \\
$\mathbf{3}$ & 6.7690 & 1.3810 & 0.4367 & 5.0283 & 8.5095 \\
$\mathbf{4}$ & 7.1364 & 1.8345 & 0.5801 & 5.0284 & 10.0567 \\
$\mathbf{5}$ & 6.9881 & 1.0818 & 0.3421 & 5.4152 & 8.2517 \\
\hline $\mathbf{0}$ & $\mathbf{M}_{\mathbf{z}} \mathbf{F}$ ratio (mm) & Standard deviation & Standard error & Minimum & Maximum \\
\hline $\mathbf{1}$ & $\infty$ & - & - & - & - \\
$\mathbf{2}$ & 15.9915 & 3.1930 & 1.010 & 12.7131 & 22.130 \\
$\mathbf{3}$ & 13.4599 & 2.1593 & 0.6828 & 9.6394 & 16.4323 \\
$\mathbf{4}$ & 11.2356 & 3.0690 & 0.9705 & 7.0752 & 15.0597 \\
$\mathbf{5}$ & 8.7403 & 2.3414 & 0.7404 & 5.6461 & 13.1960 \\
\hline
\end{tabular}

where

- $\mathrm{M}_{\mathrm{z}}=$ resultant moment about the z-axis (N.mm);

- $\mathrm{F}_{\mathrm{x}}=$ resultant force acting along the $x$-axis (N).

They also note that the $M_{y} / F_{x}$ ratio $\left(M^{*} / F\right)$ is responsible for any movements about the $\mathrm{y}$-axis (occlusal plane). These can be classified as follows:

Rotation about the $y$-axis, clockwise $\left(\mathrm{M}_{\mathrm{y}} / \mathrm{F}_{\mathrm{x}}=0\right)$;

- Translation $\left(\mathrm{M}_{\mathrm{y}} / \mathrm{F}_{\mathrm{x}}=3.5 \mathrm{~mm}\right)$;

- Rotation about the y-axis, counterclockwise $\left(\mathrm{M}_{\mathrm{y}} / \mathrm{F}_{\mathrm{x}}>3.5 \mathrm{~mm}\right)$.

The method used in the present study was able to identify all reactive forces and moments generated by the delta spring, as well as the $\mathrm{M} / \mathrm{F}$ ratios given in the literature (Ferreira et al., 2005). This type of spring has zero moment about the $\mathrm{x}$-axis $\left(\mathrm{M}_{\mathrm{x}}\right)$ and null force along the $\mathrm{z}$-axis, ensuring good geometric stability and limiting the spring's action to the sagittal and occlusal planes.

Another feature of this spring is that it does not affect dental extrusion/intrusion because the force in the $y$ direction $\left(\mathrm{F}_{\mathrm{y}}\right)$ is near zero for all activation values. Furthermore, no variations in the forces and moments were observed when the dimensions of the extremities of the spring were changed.

One advantage of 3D finite element modeling is that it requires less mathematical simplification than its 2D counterpart. Moreover, the use of 3D techniques allows the mechanical behavior in all directions and planes to be observed simultaneously, including deformation, stresses, forces and moments in any area of the delta spring. This breadth of analysis is not possible using the 2D methods that have been published to date (Ferreira et al., 2005, 2013). Table 3 shows the comparison between forces and moments found in the literature using 2D FEM and those using the 3D FEM model proposed here. As discussed above, it is not possible to obtain the My moment using 2D FEM analysis.

The results of 3D finite element modeling and experimental tests indicate that the delta orthodontic spring proposed in this paper is able to induce the following tooth movements when used in clinical practice:

Sagittal plane

- Activation of less than $1.0 \mathrm{~mm}$ : uncontrolled root tipping, counterclockwise;

- Activation between 1.0 and $4.5 \mathrm{~mm}$ : controlled root tipping, counterclockwise;

- Activation between 4.5 and $5.0 \mathrm{~mm}$ : translation;

- Activation between 5.0 and $10.0 \mathrm{~mm}$ : controlled crown tipping, clockwise.

Occlusal plane

No movement in the occlusal plane is predicted for this spring, according to the graph in Figure 5a and the $\mathrm{M} / \mathrm{F}$ ratios for this plane found in the literature (Raboud et al., 1997). 
Table 3. Comparison 2D versus 3D FEM (forces and moments).

\begin{tabular}{ccccccc}
\hline $\begin{array}{c}\text { Activation } \\
(\mathbf{m m})\end{array}$ & $\begin{array}{c}\text { Fx FEM 2D (N) } \\
\text { Ferreira et al. } \\
\mathbf{( 2 0 1 3 )}\end{array}$ & $\begin{array}{c}\text { Fx FEM } \\
\text { 3D (N) }\end{array}$ & $\begin{array}{c}\text { My FEM 2D (Nmm) } \\
\text { Ferreira et al. (2013) }\end{array}$ & $\begin{array}{c}\text { My FEM } \\
\text { 3D (Nmm) }\end{array}$ & $\begin{array}{c}\text { Mz FEM 2D (Nmm) } \\
\text { Ferreira et al. (2013) }\end{array}$ & $\begin{array}{c}\text { Mz } \\
\text { FEM 3D } \\
\mathbf{( N m m )}\end{array}$ \\
\hline $\mathbf{0}$ & 0 & 0 & Not possible to resolve & 0 & 1.57 & 2.84 \\
$\mathbf{1 . 4}$ & 0.1 & 0.25 & Not possible to resolve & 0 & 2.11 & 3.88 \\
$\mathbf{2 . 1}$ & 0.3 & 0.38 & Not possible to resolve & 0.13 & 3.2 & 4.56 \\
$\mathbf{3 . 2}$ & 0.6 & 0.57 & Not possible to resolve & 0.22 & 4.73 & 5.32 \\
$\mathbf{4 . 2}$ & 0.9 & 0.76 & Not possible to resolve & 0.33 & 6.14 & 6.02 \\
$\mathbf{5 . 1}$ & 1.2 & 0.93 & Not possible to resolve & 0.44 & 7.45 & 6.57 \\
$\mathbf{6 . 1}$ & 1.5 & 1.12 & Not possible to resolve & 0.59 & 8.66 & 7.14 \\
$\mathbf{7 . 0}$ & 1.8 & 1.3 & Not possible to resolve & 0.76 & 9.77 & 7.65 \\
$\mathbf{8 . 1}$ & 2.2 & 1.52 & Not possible to resolve & 1.0 & 11.08 & 8.17 \\
\hline
\end{tabular}

\section{References}

Ausiello P, Apicella A, Davidson CL, Rengo S. 3D finite element analysis of cusp movements in a human upper premolar, restored with adhesive resin-based composites. Journal of Biomechanics. 2001; 34(10):1269-77. http:// dx.doi.org/10.1016/S0021-9290(01)00098-7

Bourauel C, Drescher D, Ebling J, Broome D, Kanarachos A. Superelastic nickel titanium alloy retraction springs: an experimental investigation of force systems. European Journal of Orthodontics. 1997; 19(5):491-500. PMid:9386335. http://dx.doi.org/10.1093/ejo/19.5.491

Burstone CJ. The segmented arch approach to space closure. American Journal of Orthodontics. 1982; 82(5):361-78. http://dx.doi.org/10.1016/0002-9416(82)90185-3

Chen J, Isikbay SC, Brizendine EJ. Quantification of threedimensional orthodontic force systems of T-loop archwires. The Angle Orthodontist. 2010; 80(4):754-8. PMid:20482364. http://dx.doi.org/10.2319/082509-484.1

De Franco JC, Koenig HA, Burstone CJ. Three-dimensional large displacement analysis of orthodontic appliances. Journal of Biomechanics. 1976; 9(12):793-801. http:// dx.doi.org/10.1016/0021-9290(76)90187-1

Ferreira MA, Assumpção R, Luersen MA, Borges PC. Mechanical behaviour of a prototype orthodontic retraction spring: a numerical-experimental study. European Journal of Orthodontics. 2013; 35(4):414-20. PMid:21778520. http:// dx.doi.org/10.1093/ejo/cjr062

Ferreira MA, Borges PC, Luersen MA. Alguns aspectos da mecânica das alças de retração ortodôntica. Revista Dental Press de Ortodontia e Ortopedia Facial. 2008; 13(3):11223. http://dx.doi.org/10.1590/S1415-54192008000300014

Ferreira MA, Oliveira FT, Ignacio SA, Borges PC. Experimental force definition system for a new orthodontic retraction spring. The Angle Orthodontist. 2005; 75(3):334-43.

Fotos PG, Spyrakos CC, Bernard DO. Orthodontic forces generated by a simulated archwire appliance evaluated by the finite element method. The Angle Orthodontist. 1987; 60(4):277-81.
Fraunhofer JA, Bonds PW, Johnson BE. Force generation by orthodontic coil springs. The Angle Orthodontist. 1993; 63(2):145-8.

Geramy A, Retrouvey JM, Shalchi M, Salehi H. Loop position in anterior retraction arch wire and its effects on the produced forces: $3 \mathrm{~d}$ analysis using finite element method. International Journal of Clinical Dentistry. 2012; 5(2):121-30.

Guan H, Van Staden RC, Johnson NW, Loo YC. Dynamic modeling and simulation of dental implant insertion process: a finite element study. Finite Elements in Analysis and Design. 2011; 47(8):886-97. http://dx.doi.org/10.1016/j. finel.2011.03.005

Hutton DV. Fundamentals of finite element analysis. Pullman: The McGraw-Hill Companies; 2004. v. 1.

Katona RT, Le YP, Chen J. The effects of first- and secondorder gable bends on forces and moments generated by triangular loops. American Journal of Orthodontics \& Dentalfacial Orthopedics. 2006; 129(1):54-9. PMid:16443479. http://dx.doi.org/10.1016/j.ajodo.2004.10.009

Koenig HA, Burstone CJ. Analysis of generalized curved beams of orthodontic applications. Journal of Biomechanics. 1974; 7(5):429-35. http://dx.doi. org/10.1016/0021-9290(74)90005-0

Kojima Y, Fukui H. Numerical simulations of canine retraction with T-loop springs based on the updated moment-to-force ratio. European Journal of Orthodontics. 2012; 34(1):108. PMid:21135033. http://dx.doi.org/10.1093/ejo/cjq164

Lotti RS, Mazzieiro ET, Landre J Jr. A influência do posicionamento ântero-posterior da alça $\mathrm{T}$ segmentada durante o movimento de retração inicial: uma avaliação pelo método dos elementos finitos. Revista Dental Press de Ortodontia e Ortopedia Facial. 2006; 11(3):41-54. http:// dx.doi.org/10.1590/S1415-54192006000300006

Raboud DW, Faulkner MG, Lipsett AW, Haberstock DL. Three-dimensional effects in retraction appliance design. The Angle Orthodontist. 1997; 112(4):378-92. http://dx.doi. org/10.1016/S0889-5406(97)70046-5

Romeed SA, Fok SL, Wilson NHF. A comparasion of 2D and 3D finite element analysis of a restored tooth. Journal of Oral Rehabilitation. 2006; 33(3):209-15. PMid:16512887. http://dx.doi.org/10.1111/j.1365-2842.2005.01552.x 
Techalertpaisarn P, Versluis A. Mechanical properties of opus closing loops, l-loops, and t-loops investigated with finite element analysis. American Journal of Orthodontics and Dentofacial Orthopedics. 2013; 143(5):67583. PMid:23631969. http://dx.doi.org/10.1016/j. ajodo.2013.01.011
Xavier TA, Ballester RY. A comparison between the capacity of 2D and 3D finite element models in analyzing the stress distribution in shear and microshear bond strength tests. Journal of Research in Dentistry. 2013; 1(1):41-54.

Zienkiewicz OC, Taylor RL. The finite element method. 5th ed. Woburn: Butterworth Heinemann; 2000. v. 1.

\section{Authors}

Fábio Rodrigo Mandello Rodrigues*

Postgraduate Program in Electrical Engineering and Industrial Computing - CPGEI, Federal Technological University of Paraná - UTFPR, Av. Sete de Setembro, 3165, Rebouças, CEP 80230-901, Curitiba, PR, Curitiba, PR, Brazil.

Fábio Rodrigo Mandello Rodrigues, Paulo César Borges, Marco Antônio Luersen

Department of Mechanical Engineering - DAMEC, Federal Technological University of Paraná - UTFPR, Curitiba, PR, Brazil. 